\title{
Complications and their treatment after midurethral tape implantation using retropubic and transobturator approaches for treatment of female stress urinary incontinence
}

\author{
Marija Barisiene, Ausra Cerniauskiene, Augustinas Matulevicius \\ Clinic of Gastroenterology, Nephrourology and Surgery, Center of Urology, Faculty of Medicine, Vilnius University, Vilnius, Lithuania \\ Videosurgery Miniinv 2018; 13 (4): 501-506 \\ DOI: https://doi.org/10.5114/wiitm.2018.75871
}

\begin{abstract}
Introduction: Midurethral tape implantation procedures currently are the first-line treatment for female stress urinary incontinence (SUI).

Aim: To estimate the most common intraoperative and postoperative complications and their treatment methods after midurethral tape implantation using retropubic (tension-free vaginal tape - TVT) and transobturator (TOT) approaches for the treatment of female SUI.

Material and methods: A retrospective descriptive study was performed on 367 women operated on due to SUI in the period from 2004 to 2015. The SUI diagnosis was confirmed by clinical history and physical examination. According to the surgical technique that was chosen for SUI treatment, all the patients were divided into two groups: the TVT group ( $n=112)$ and the TOT group $(n=255)$.

Results: In total, in 31 (8.45\%) of 367 patients complications were observed after midurethral tape implantation. In the TVT group 18 (16.07\%) of 112 patients experienced surgery-related complications compared to 13 (5.1\%) of 255 patients in the TOT group $(p=0.0005)$. The most common intraoperative complication in the TVT group was bladder perforation. In the TOT group we had only occasional intraoperative complications. Acute urinary retention was the most common postoperative complication in both groups. It was observed in 13 (11.6\%) patients in the TVT group and in 5 (1.96\%) patients in the TOT group.

Conclusions: The advantage of midurethral tape implantation using the TOT technique is that it is associated with lower incidence of intraoperative and postoperative complications compared to TVT. The most common complication in our series was acute postoperative urinary retention, which usually required an additional tape loosening procedure.
\end{abstract}

Key words: complications, stress urinary incontinence, tension-free vaginal tape, transobturator tape.

\section{Introduction}

Stress urinary incontinence (SUI) is defined as a complaint of involuntary loss of urine on effort or physical exertion (e.g., sporting activities), or on sneezing or coughing [1]. Stress urinary incontinence has been estimated to affect $50 \%$ of all women [2]. It is negatively associated with patient quality of life, imposes high costs on healthcare systems and negatively affects socioeconomics [3].

In 1996, Ulmsten et al. described a new minimally invasive technique, a tension-free polypropylene mesh vaginal tape (TVT) procedure for female urinary incontinence treatment [4]. Complications such as bladder perforation and retropubic hematoma re- 
lated to the passage of the tape through the retropubic space have been reported [5]. With the tendency to minimize these complications, in 2001, the French urologist Delorme described another minimally invasive tape insertion route through small incisions in the groin, passing the obturator foramina, and in the vagina under the middle part of the urethra, which the author called transobturator taping (TOT) [6]. In 2003, de Leval introduced a modified technique called TVT-O, in which the tape is inserted in a reverse route, in through a vaginal incision and out through the obturator foramen (inside out) [7]. Both the TOT and TVT-O procedures proved to be associated with few peri-operative complications [8]. This operative technique allowed a reduction of the risk of bladder and bowel perforation, and major vascular injury [9-11], also voiding dysfunction that can occur with TVT, but has been reported to be associated with higher incidence of groin pain $[12,13]$.

Currently, the midurethral tape implantation procedures are the first-line treatment for female SUI [14].

In 2008, the Food and Drug Administration (FDA) warned of potentially serious complications associated with surgical mesh placed through the vagina to treat pelvic organ prolapse (POP) and SUI. In 2014 mesh usage for POP repair was suspended by the Scottish government. Therefore, the review and analysis of midurethral tape implantation complications is very important and relevant.

\section{Aim}

The aim of our study was to estimate the most common intraoperative and postoperative complications and their treatment methods after midurethral tape implantation using retropubic (tension-free vaginal tape - TVT) and transobturator (TOT) approaches for the treatment of female SUI.

\section{Material and methods}

A retrospective descriptive study was performed on 367 women operated on due to stress urinary incontinence at the Urology Centre of the Vilnius University Hospital Santaros Klinikos in the period from January 2004 to September 2015. The stress urinary incontinence diagnosis was confirmed by clinical history and physical examination. The physical examination included a cough test and the Ulmsten test. Also urinalysis, urine culture, if needed, urogen- ital ultrasound, and the measurement of post-void residual urine were performed. According to the surgical technique that was chosen for SUI treatment, all the patients were divided into two groups: in the TVT group ( $n=112)$ the midurethral tape was inserted by the retropubic route, and in the TOT group ( $n=255)$ the tape was inserted by the transobturator route using the 'outside-in' technique. The surgery for stress urinary incontinence and the further follow-up for a period of 6 months after the surgery was performed by one experienced urologist; thus, the results are comparable. The following data such as age, body mass index (BMI), the degree of urinary incontinence prior to the surgery, deliveries, menopause status, the history of hysterectomy in the past, previous surgery due to stress urinary incontinence or pelvic organ prolapse (POP) were also collected.

All patients underwent routine physical and vaginal examination, including a cough test, and postvoid residual urine volume measurement after 1 and 6 months after the surgery.

We described the intraoperative and postoperative complications related to the surgery in each group, and the treatment methods performed to resolve the complications.

\section{Statistical analysis}

We used SPSS version 21.0 and Microsoft Excel 2010 for statistical analysis. $P$-values $<0.05$ were considered statistically significant. For statistical analysis we used Student's $t$-test, the $\chi^{2}$ test, and the Wilcoxon test.

\section{Results}

The characteristics of patients in TVT and TOT groups are shown in Table I. We did not find any differences between the groups in age, deliveries, hysterectomy in the past, or previous surgery due to SUI or POP ( $p>0.05)$. We found statistically significant higher BMI in the TVT group compared to the TOT group, with BMI being $30.44 \pm 4.9 \mathrm{~kg} / \mathrm{m}^{2}$ in the TVT group and $25.29 \pm 4.17 \mathrm{~kg} / \mathrm{m}^{2}$ in the TOT group $(p=0.0023)$. This can be explained by our preference to perform the TVT operation in women with overweight and obesity, because there are publications that show better continence results in these patients, particularly after the TVT compared to the TOT procedure. 
Table I. Characteristics of patients in TVT and TOT groups

\begin{tabular}{|c|c|c|c|}
\hline Parameter & $\begin{array}{l}\text { TVT group } \\
(n=112)\end{array}$ & $\begin{array}{l}\text { TOT group } \\
(n=255)\end{array}$ & $P$-value \\
\hline Age [years] & $58.38 \pm 10.68^{*}$ & $52.85 \pm 10.74^{*}$ & 0.0827 \\
\hline $\mathrm{BMI}\left[\mathrm{kg} / \mathrm{m}^{2}\right]$ & $30.44 \pm 4.9^{*}$ & $25.29 \pm 4.17^{\star}$ & 0.0023 \\
\hline \multicolumn{4}{|c|}{ Degree of urinary incontinence prior to surgery: } \\
\hline$\|$ & $55.56 \%$ & $84.62 \%$ & \\
\hline III & $44.44 \%$ & $15.38 \%$ & \\
\hline Deliveries & $1.89 \pm 0.68^{*}$ & $1.54 \pm 0.78^{\star}$ & 0.1017 \\
\hline \multicolumn{4}{|l|}{ Postmenopausal: } \\
\hline Yes & $83.33 \%$ & $61.54 \%$ & \\
\hline No & $16.67 \%$ & $38.46 \%$ & \\
\hline $\begin{array}{l}\text { Hysterectomy in } \\
\text { past }\end{array}$ & $5.56 \%$ & $23.08 \%$ & 0.1510 \\
\hline $\begin{array}{l}\text { Previous surgery } \\
\text { due to SUI or POP }\end{array}$ & $27.78 \%$ & $15.38 \%$ & 0.4150 \\
\hline
\end{tabular}

In total, in 31 (8.45\%) of 367 patients, intraoperative or postoperative complications were observed after midurethral tape implantation. In the TVT group $18(16.07 \%)$ of 112 patients experienced surgery-related complications compared to 13 (5.1\%) of 255 patients in the TOT group. The difference between the groups was statistically significant $(p=0.0005)$.

The most common intraoperative complication in the TVT group was bladder perforation. It was observed in $2(1.79 \%)$ patients. In the TOT group we had only occasional intraoperative complications such as bladder neck and urethral injury with the incidence of $0.39 \%$ of 255 patients.

Acute urinary retention was the most common postoperative complication in both groups. It was observed in $13(11.6 \%)$ patients in the TVT group and in 5 (1.96\%) patients in the TOT group.

Incidence of complications in TOT and TVT groups is presented in Table II.

\section{Description of complications and their treatment}

We observed 3 (2.68\%) intraoperative complications in the TVT group $(n=112)$. In $2(1.79 \%)$ cases bladder perforation during the passage of the needle through the retropubic space, and in 1 (0.89\%) case urethral injury during the urethro-vaginal dissection occurred. In both cases of bladder perforation it was
Table II. Incidence of complications in TVT and TOT groups

\begin{tabular}{|c|c|c|c|}
\hline Parameter & $\begin{array}{l}\text { TVT group } \\
(n=112)\end{array}$ & $\begin{array}{l}\text { TOT group } \\
(n=255)\end{array}$ & $P$-value \\
\hline \multicolumn{4}{|l|}{ Intraoperative: } \\
\hline $\begin{array}{l}\text { Bladder } \\
\text { perforation }\end{array}$ & $2(1.79 \%)$ & 0 & \\
\hline $\begin{array}{l}\text { Bladder neck } \\
\text { perforation }\end{array}$ & 0 & $1(0.39 \%)$ & \\
\hline Urethral injury & $1(0.89 \%)$ & $1(0.39 \%)$ & \\
\hline \multicolumn{4}{|l|}{ Postoperative: } \\
\hline $\begin{array}{l}\text { Acute urinary } \\
\text { retention }\end{array}$ & $13(11.6 \%)$ & $5(1.96 \%)$ & \\
\hline $\begin{array}{l}\text { Chronic urinary } \\
\text { retention }\end{array}$ & 0 & $3(1.18 \%)$ & \\
\hline $\begin{array}{l}\text { Difficulty on } \\
\text { voiding }\end{array}$ & $1(0.89 \%)$ & $1(0.39 \%)$ & \\
\hline $\begin{array}{l}\text { Retropubic } \\
\text { hematoma }\end{array}$ & $1(0.89 \%)$ & 0 & \\
\hline $\begin{array}{l}\text { Urinary tract } \\
\text { infection }\end{array}$ & 0 & $1(0.39 \%)$ & \\
\hline Inguinal pain & 0 & $1(0.39 \%)$ & \\
\hline $\begin{array}{l}\text { Total complication } \\
\text { rate }\end{array}$ & 18 (16.07\%) & $13(5.1 \%)$ & 0.0005 \\
\hline
\end{tabular}

detected on intraoperative cystoscopy, the needle was reinserted properly, and tape implantation was performed. On postoperative day 6 and 4 respectively due to suprapubic pain and leakage through the suprapubic incision, midurethral tape was removed in both cases. The injury of the proximal urethra was resolved by suture, the midurethral tape was inserted, and the bladder catheter was removed on day 14 postoperatively without any further consequences.

Acute urinary retention was the most frequent postoperative complication in the TVT group and it was observed in 13 (11.6\%) patients. In 12 cases the midurethral tape was pulled down until the $8^{\text {th }}$ postoperative day; 1 of these patients needed repeated tape loosening. In 1 woman the midurethral tape was cut on the $17^{\text {th }}$ postoperative day. One $(0.89 \%)$ woman improved after intermittent bladder catheterization for 4 days due to difficulty on voiding. In 1 (0.89\%) case retropubic hematoma was evacuated by the open approach.

We observed 2 (0.78\%) intraoperative complications in the TOT group $(n=255)$. In 1 (0.39\%) woman bladder neck perforation was resolved by suture, 
the midurethral tape was inserted, and the bladder catheter was removed on the $8^{\text {th }}$ postoperative day successfully. In 1 (0.39\%) patient urethral injury was observed after the tape insertion, the tape was removed, and the urethral injury resolved by suture leaving the urethral catheter for 14 days.

Acute urinary retention was the most frequent postoperative complication in the TOT group as well as in the TVT group. It was observed in 5 (1.96\%) patients. In all cases the midurethral sling was pulled down until the $8^{\text {th }}$ postoperative day. In 3 (1.18\%) women partial midurethral sling resection or cut-off due to chronic urinary retention and straining on urination after 4 and 6 months after the midurethral tape implantation was performed. One (0.39\%) woman needed intermittent bladder catheterization for 5 days due to difficulty on voiding. In 1 (0.39\%) patient acute urinary tract infection was resolved by oral antibiotics. One (0.39\%) woman suffered from inguinal pain after the operation, which resolved in
3 months after administration of non-steroid antiinflammatory drugs and local analgesic blockage.

The complications and their treatment methods in both groups are presented in Tables III and IV.

\section{Discussion}

Midurethral tape implantation procedures are minimally invasive and currently appreciated as the first-line treatment for female SUI. We estimated that the incidence of complications in TVT and TOT groups with up to six months follow-up postoperatively was $16.07 \%$ and $5.1 \%$ respectively $(p=$ $0.0005)$. The overall incidence of complications in both groups was $8.45 \%$.

The incidence rates of complications after midurethral tape procedures reported in different studies are controversial.

Despite the fact that TVT is a minimally invasive technique, such complications as bowel perforation

Table III. Treatment methods of intraoperative and postoperative complications in TVT group

\begin{tabular}{|c|c|}
\hline Complication & Treatment \\
\hline \multicolumn{2}{|l|}{ Intraoperative: } \\
\hline Bladder perforation & Needle reinsertion during the operation $\rightarrow$ leakage through the suprapubic incision $\rightarrow$ sling removal \\
\hline Urethral injury & Suture, bladder catheter for 14 days \\
\hline \multicolumn{2}{|l|}{ Postoperative: } \\
\hline Acute urinary retention & $\begin{array}{l}\text { Sling pulled down until } 8^{\text {th }} \text { postoperative day, in } 1 \text { case the procedure was repeated, in } 1 \text { case } \\
\text { the sling was cut on the } 17^{\text {th }} \text { post-op day }\end{array}$ \\
\hline Difficulty on voiding & Intermittent catheterization \\
\hline Retropubic hematoma & Evacuation by open approach \\
\hline
\end{tabular}

Table IV. Treatment methods of intraoperative and postoperative complications in TOT group

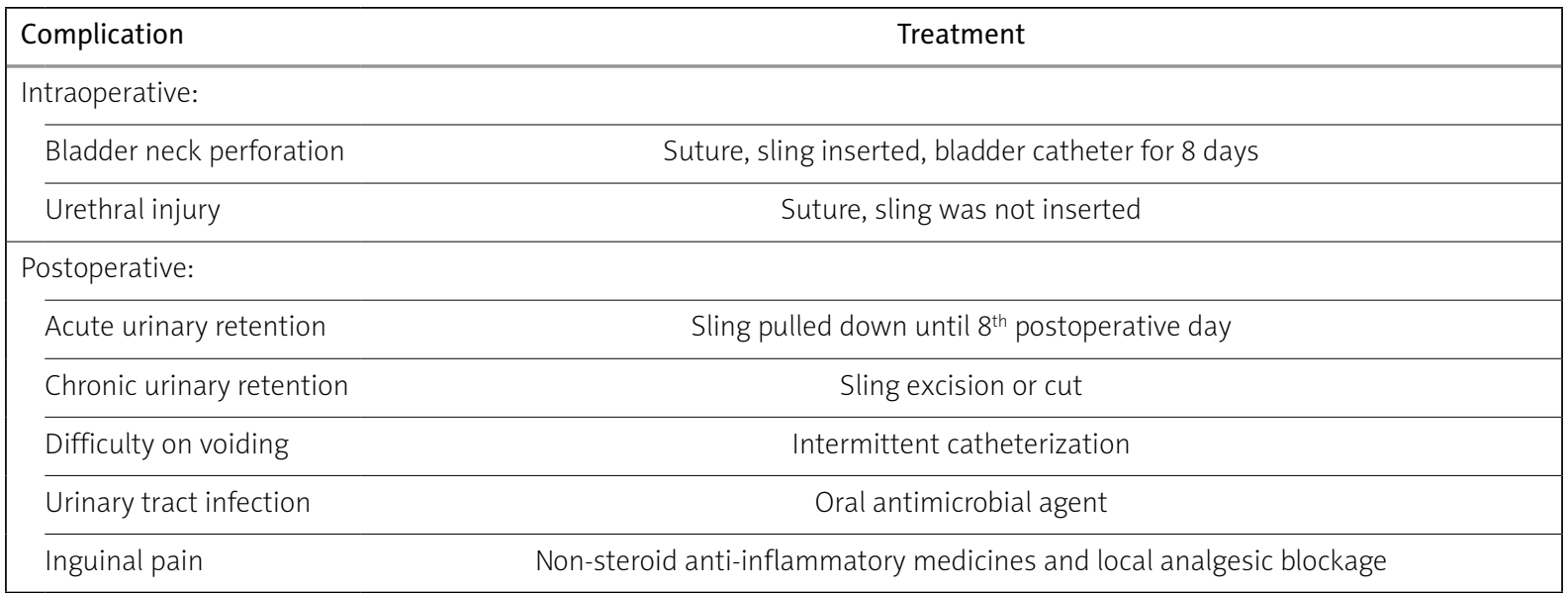


and major vascular injury in rare cases may occur [15]. Richter et al. in their 1-year randomized controlled trial that included 597 patients found that the number of patients with serious adverse events in the retropubic group was greater than the number in the transobturator group (13.8\% vs. $6.4 \%)$, but they did not find a difference in the incidence of adverse events [2].

In our study population, we did not observe any serious or life-threatening complications.

The bladder perforation incidence in the TVT group was $1.79 \%$, and we did not have any in the TOT group. Despite the fact that in two bladder perforation cases in our study we had to remove the midurethral tape, due to very low incidence we cannot draw conclusions on the severity of this complication. There are publications showing that usually bladder perforations do not result in any clinically significant morbidity [16]. To reduce the possibility of bladder injury during the TVT procedure we routinely use a bladder shifting maneuver to the opposite side during the needle passage through the retropubic space. Also we routinely perform intraoperative cystoscopy after the sling implantation to rule out bladder injury. We do not routinely perform cystoscopy during transobturator sling implantation like most others centers in Europe, as TOT had a significantly lower risk of bladder perforations [3]. Thus, the real bladder perforation rate during the TOT procedure may be a little higher. We suggest performing intraoperative cystoscopy during the TOT procedure if the surgeon suspects bladder injury or notices objective bladder injury signs, such as hematuria.

Postoperative voiding disturbances, such as acute urinary retention and difficulty on voiding, were diagnosed more commonly after the TVT procedure (11.6\% and $0.89 \%$ respectively) compared to TOT (1.96\% and $0.39 \%$ respectively). There are some treatment options to resolve this complication, such as clean intermittent catheterization, tape mobilization or tape division. Approximately $2.4 \%$ to $3.5 \%$ of women after the TVT procedure requiring tape mobilization. The optimal time for tape mobilization is within 2 weeks postoperatively [17]. In our practice we rarely perform intermittent bladder catheterization for longer than 1 week. If normal voiding does not recover within several days, we usually perform early sling mobilization within 1 week postoperatively.

There are reports that postoperative urinary tract infections are more common in the retropubic group [18]. However, we did not observe any urinary tract infection in the TVT group, and the incidence of urinary tract infections in the TOT group was $0.39 \%$.

We had only 1 woman with persistent groin pain after the midurethral sling implantation in the TOT group with the incidence of $0.39 \%$. A Cochrane review suggested that the transobturator procedure had a higher incidence of groin pain at 12 months postoperatively [19]. Zahn et al., examining the issue from the anatomical point of view, compared the two methods regarding the proximity of the tape to the obturator canal and ischiopubic ramus in fresh frozen cadavers and concluded that the outside-in technique reduces the risk of neurovascular injury more effectively than the inside-out procedure [20].

We had no cases of tape erosion or exposure reported in our study. In the literature the reported incidence of tape exposure after TVT and transobturator tape implantation ranges from $3.8 \%$ to $15 \%$ [10]. Also late presentations of tape exposure have been reported [18].

The limitation of our study is the relatively short follow-up period to appropriately reflect long-term midurethral sling complications, particularly sling erosion and exposure, chronic pain, and de-novo urgency.

In the opinion of the majority authors the transobturator approach is associated with a lower complication rate than TVT $[3,21]$, which is consistent with our study results.

\section{Conclusions}

The advantage of midurethral tape implantation using the TOT technique is that it is associated with lower incidence of intraoperative and postoperative complications compared to TVT. The character of our described complications were similar to those reported in the literature, and the prevalence and incidence of complications were even lower. The most common complication in our series was acute postoperative urinary retention, which usually required an additional tape loosening procedure.

It is very important to suspect, detect early and properly treat the particular complication.

\section{Conflict of interest}

The authors declare no conflict of interest. 


\section{References}

1. Haylen BT, de Ridder D, Freeman RM, et al. An International Urogynecological Association (IUGA)/International Continence Society (ICS) joint report on the terminology for female pelvic floor dysfunction. Neurourol Urodyn 2010; 29: 4-20.

2. Richter HE, Albo ME, Zyczynski HM, et al. Retropubic versus transobturator midurethral slings for stress incontinence. N Eng J Med 2010; 362: 2066-76.

3. Novara G, Artibani W, Barber MD, et al. Updated systematic review and meta-analysis of the comparative data on colposuspensions, pubovaginal slings, and midurethral tapes in the surgical treatment of female stress urinary incontinence. Eur Urol 2010; 58: 218-38.

4. Ulmsten $U$, Henriksson L, Johnson P, et al. An ambulatory surgical procedure under local anaesthesia for treatment of female urinary incontinence. Int Urogynecol J Pelvic Floor Dysfunct 1996; 7: 81-5.

5. Karram MM, Segal J, Vassallo BJ, et al. Complications and untoward effects of the tension-free vaginal tape procedure. Obstet Gynecol 2003; 101: 929-32.

6. Delorme E. Transobturator urethral suspension: mini-invasive procedure in the treatment of stress urinary incontinence in women. Prog Urol 2001; 11: 1306-13.

7. de Leval J. Novel surgical technique for the treatment of female stress urinary incontinence: transobturator vaginal tape insideout. Eur Urol 2003; 44: 724-30.

8. Rajendra M, Han HC, Lee LC, et al. Retrospective study on tension-free vaginal tape obturator (TVT-O). Int Urogynecol J 2012; 23: $327-34$

9. Xylinas E, Descazeaud A. Repeat midurethral sling for female stress urinary incontinence after failure of the initial sling. Prog Urol 2009; 19: 590-4.

10. Porena M, Costantini E, Frea B, et al. Tension-free vaginal tape versus transobturator tape as surgery for stress urinary incontinence: results of a multicentre randomised trial. Eur Urol 2007; 52: 1481-90.

11. Ayhan A, Dogan NU, Guven S, et al. Clinical outcome of transobturator tape concomitant with vaginal hysterectomy plus anterior posterior colporrhaphy. Arch Gynecol Obstet 2009; 280: 375-80.

12. Ogah J, Cody JD, Rogerson L. Minimally invasive synthetic suburethral sling operations for stress urinary incontinence in women. Cochrane Database Syst Rev 2009; 4: CD006375.

13. Sun X, Yang Q, Sun F, et al. Comparison between the repropubic and transobturator approaches in the treatment of female stress urinary incontinence: a systematic review and meta-analysis of the effectiveness and complications. Int Braz J Urol 2015; 41: 220-9.

14. Tantanasis T, Daniilidis A, Pantelis A, et al. Minimally invasive techniques for female stress urinary incontinence, how, why, when. Arch Gynecol Obstet 2013; 288: 995-1001.

15. Ward KL, Hilton P. A prospective multicenter randomised trial of tension-free vaginal tape and colposuspension for primary urodynamic stress incontinence: two-year follow up. Am J Obstet Gynecol 2004; 190: 324-31.

16. Houwert RM, Roovers JP, Venema PL, et al. Outcome and complications of retropubic and transobturator midurethral slings translated into surgical therapeutic indices. Am J Obstet Gynecol 2010; 202: e1-7.

17. Price N, Slack A, Khong S, et al. The benefit of early mobilisation of tension-free vaginal tape in the treatment of post-operative voiding dysfunction. Neurourol Urodyn 2009; 20: 855-8.

18. Albo ME, Litman HJ, Rihter HE, et al. Treatment success of retropubic and transobturator mid urethral slings at 24 months. J Urol 2012; 188: 2281-7.

19. Ogah J, Cody JD, Rogerson L. Minimally invasive synthetic suburethral sling operations for stress urinary incontinence in women: a short version Cochrane review. Neurourol Urodyn 2011; 30: 284-91.

20. Zahn CM, Siddique S, Hernandez S, et al. Anatomic comparison of two transobturator tape procedures. Obstet Gynecol 2007; 109: 701-6.

21. Long CY, Hsu CS, Wu MP, et al. Comparison of tension-free vaginal tape and transobturator tape procedure for the treatment of stress urinary incontenence. Curr Opin Obstet Gynecol 2009; 21: $342-7$.

Received: 2.03.2018, accepted: 21.03.2018. 